\title{
Preventive Effect of Lactobacillus acidophilus XY27 on DSS-Induced Ulcerative Colitis in Mice
}

This article was published in the following Dove Press journal:

Drug Design, Development and Therapy

\author{
Tiantian $\mathrm{Hu}\left(\mathbb{D D}^{1-3, *}\right.$ \\ Hongxia Wang ${ }^{4, *}$ \\ Chengzheng Xiang ${ }^{1-3}$ \\ Jianfei $\mathrm{Mu}^{\mathrm{I}-3}$ \\ Xin Zhao $\mathbb{D}^{1-3}$ \\ 'Chongqing Collaborative Innovation \\ Center for Functional Food, Chongqing \\ University of Education, Chongqing, \\ People's Republic of China; ${ }^{2}$ Chongqing \\ Engineering Research Center of \\ Functional Food, Chongqing University of \\ Education, Chongqing, People's Republic \\ of China; ${ }^{3}$ Chongqing Engineering \\ Laboratory for Research and \\ Development of Functional Food, \\ Chongqing University of Education, \\ Chongqing, People's Republic of China; \\ ${ }^{4}$ Department of Paediatrics, Haikou \\ Affiliated Hospital of Central South \\ University Xiangya School of Medicine \\ (Haikou People's Hospital), Haikou, \\ Hainan, People's Republic of China
}

*These authors contributed equally to this work
Introduction: Lactobacillus acidophilus is widely used as probiotic supplement in functional foods due to its beneficial regulatory effects on host, such as immune regulation, antiinflammatory, and antioxidant activities.

Aim: This study aimed to determine the preventive effect of Lactobacillus acidophilus XY27 (L. acidophilus XY27) on colitis induced by dextran sodium.

Methods: The mice were randomly divided into five groups. Except for the control group, the other four groups were induced for ulcerative colitis (UC) with dextran sodium sulfate (DSS), and three groups in DSS-groups were treated with L. acidophilus XY27, L. bulgaricus, and salicylazosulfapyridine. The weight change, DAI score, colon length, and length to weight ratio were tested. The oxidation index and the levels of inflammatory cytokines in the serum were measured. Subsequently, the gene expression levels of inflammatory factors in the colon tissue were determined by the Real-Time quantitative polymerase chain reaction (qRT-PCR) method.

Results: The results showed that the mice in the L. acidophilus XY27 group performed better in terms of weight, DAI score, colon length, and length to weight ratio or colonic pathological sections compared with the DSS-induced group. Further, the levels of tumor necrosis factor $\alpha$ (TNF- $\alpha$ ), Interleukin-6 (IL-6), Interleukin-12 (IL-12) and Interleukin-1 $\beta$ (IL-1 $\beta$ ), malondialdehyde (MDA) content, and myeloperoxidase activity in the serum of UC mice treated with L. acidophilus XY27 significantly decreased, while the levels of Interferon$\gamma$ (IFN- $\gamma$ ), Interleukin-10 (IL-10), Catalase (CAT), and total superoxide dismutase (SOD) significantly increased. The gene expression levels of Ets-like transcription factor-1 (EIK-1), IL-12, IL-1 $\beta$, Cyclooxygenase 2 (COX-2), TNF- $\alpha$, Escherichia coli, Lipopolysaccharide (LPS), and p100 in the colon significantly decreased while those of tight junction protein 1 (ZO-1), nuclear factor kappa B (NF-kB), p53, and NF-kappa-B inhibitor alpha (IкB- $\alpha$ ) increased in the L. acidophilus XY27 group.

Conclusion: The results of the experiment suggested that L. acidophilus XY27 prevented colitis and alleviated symptoms in mice with DSS-induced UC, and also repaired the intestinal barrier function.

Keywords: dextran sodium sulfate, Lactobacillus acidophilus XY27, Lactobacillus bulgaricus, ulcerative colitis

\section{Introduction}

Inflammatory bowel disease (IBD) is a chronic, recurrent, long-term inflammatory disease that eventually leads to colonic and rectal ulcers, including Crohn's disease (CD) and ulcerative colitis (UC). At present, no specific treatment is available for UC. Anti-inflammatory drugs and immunosuppressants are used mainly to relieve symptoms, which are effective only in the early stages of the disease with some side 
effects. ${ }^{1}$ Hence, more safe strategies for preventing and treating UC need to be explored.

The pathogenesis of UC is complex and related to both genetic and environmental factors. No matter what the exact mechanism of inducing and maintaining enteritis is, sufficient evidence shows that a strong local immune response is involved. Immune cells receive signals and are recruited and activated. They release soluble cytokines and inflammatory mediators and cause more serious inflammation and tissue damage, leading to the amplification and enhancement of local immune response. ${ }^{2}$ Inflammatory mediators, especially cytokines, mediate the proliferation and differentiation of immune cells, regulate inflammatory cells, and balance the function of the intestinal mucosal barrier, thus playing a role in the immune response. ${ }^{3}$ The relative expression levels of TNF- $\alpha$, IL-1 $\beta$, IFN- $\gamma$, IL-12, IL-6 EIK-1, COX-2, E. coli, LPS, and p100 genes increased in patients with colitis, the relative expression levels of ZO-1, NF-kB, p53, and IKB- $\alpha$ genes decreased, and the contents of some of these factors were changed on the first day after DSS induction. ${ }^{4}$ The changes in the levels of inflammatory cytokines in colonic mucosa are the main causes of intestinal mucosal inflammatory injury and ulcers.

Many studies showed an important role of the intestinal flora in the mucosal immune response in intestinal diseases and inflammation. ${ }^{1,5,6} \mathrm{UC}$ can be treated by regulating intestinal flora and increasing the number of probiotic. ${ }^{7-9}$ Therefore, increasing attention was paid to the potential and beneficial roles of probiotics in the control and regulation of IBD. Meta-analyses and systematic review reports showed that probiotics were beneficial to the treatment of IBD, especially the combined use of probiotics in treating UC. ${ }^{10}$ Millions of people worldwide consume probiotics, and the market size of probiotics is expected to reach nearly US $\$ 70$ billion by $2023 .{ }^{11}$ Among these, Lactobacillus, as important commercial probiotics, is widely added to functional foods worldwide.

Lactobacillus acidophilus, which is a homofermentative species, is now one of the most typical Lactobacillus genera commonly used for various beneficial effects on human health. ${ }^{12}$ L. acidophilus can not only decrease blood cholesterol, lactose, and the risk of constipation and diarrhea but also reduce the risk of mutation and carcinogenesis. L. acidophilus is recognized as a probiotic strain with anticancer and cholesterol-lowering properties, as well as an antagonist against intestinal and foodborne pathogens. It can survive in harsh environments and complex gastrointestinal ecosystems. ${ }^{11,13}$ The beneficial effect of L. acidophilus lasts longer compared with that of microorganisms that cannot settle in the intestinal tract, and it is a potential strain. ${ }^{14}$ The anticancer and cholesterollowering characteristics, as well as the antagonism against intestinal and food pathogenic bacteria, are usually achieved by affecting the homeostasis of intestinal flora; its mechanism is under investigation. ${ }^{14}$ Intestinal flora and probiotics are vital in the occurrence, development, and treatment of UC. Probiotic can regulate inflammatory response by stimulating cells to produce cytokines. In particular, some Lactobacillus and Bifidobacterium genus can activate macrophages, natural killer (NK) cells, and $\mathrm{T}$ lymphocytes of the host to regulate the immune system. However, the evidence for the clinical effect of probiotics on these diseases is not sufficient probably because the individual differences and the health effect of probiotics are strain specific. Huge genomic diversity exists among different strains of Lactobacillus. The in vitro determination of many probiotics and animal model data showed that the efficacy was different among the potential probiotic strains tested. ${ }^{9}$ Different probiotics have different effects on different diseases because of strain and disease specificity. Therefore, it is very meaningful to find and verify strains with good efficacy. ${ }^{15}$

An effective probiotic to prevent and treat $\mathrm{UC}$ needs to be urgently developed. In this study, the preventive and therapeutic effects of $L$. acidophilus XY27 on DSS-induced UC were verified through detecting the colonic histological, blood and tissue-related inflammatory factors, oxidative stress factors of mice. This research aimed to obtain a Lactobacillus strain with the potential to ameliorate colitis.

\section{Materials and Methods}

\section{Preparation of L. acidophilus}

Source of $L$. acidophilus

L. acidophilus XY27 used in this study was isolated and identified from the traditional fermented yak yogurt samples of herdsmen in Xinyuan County, Northwest Xinjiang Uygur Autonomous region, China. The preservation number is CGMCC No. 18227 in China General Microbiological Culture Collection Center, Beijing, China (hereafter referred to as LA-XY27).

\section{Activation of $L$. acidophilus}

LA-XY27 frozen in glycerol was dissolved in the bath, inoculated in a $5 \mathrm{~mL}$ of MRS medium, and further cultured at $37^{\circ} \mathrm{C}$ for 1 day. Subsequently, it was activated 
again in the liquid medium after growth. After LA-XY27 preparation, Gram staining was used and the microscopic examination was performed to observe whether the strains were contaminated. The number of live bacteria and the absorbance of the original solution were calculated by plate counting and absorbance measurement.

\section{Preparation of the Suspension}

The purebred colonies were inoculated on $5 \mathrm{~mL}$ of MRS medium and cultured at $37^{\circ} \mathrm{C}$ for $24 \mathrm{~h}$. Then, $1 \mathrm{~mL}$ of the medium containing bacteria was centrifuged at $4000 \mathrm{rpm}$ for $10 \mathrm{~min}$. The supernatant was taken, and the bacteria were resuspended in sterile saline and finally stained.

Further, $200 \mu \mathrm{L}$ of sample bacteria were poured into the aseptic medium and cultured in an incubator at $37^{\circ} \mathrm{C}$ for 16-40 h. The culture medium containing bacteria was centrifuged for $10 \mathrm{~min}$ at the speed of $4000 \mathrm{rpm}$. The supernatant was discarded, and the bacteria at the bottom were retained. The bacteria were resuscitated with $5 \mathrm{~mL}$ of aseptic saline. Finally, the OD value of the bacterial suspension was determined, which was about 1.9. The suspension could be used for gavage administration.

\section{Animal Experiment}

The experimental protocol is shown in Figure 1. Fifty C57BL/6 mice (SPF grade, male, aged 6 weeks) were purchased from Chongqing Medical University and adaptively fed in an environment at constant temperature and humidity for a week. Fifty mice were randomly divided into five groups $(n=10)$ : control group (C-G), DSS group (DSSG), LA-XY27 group (LA-G), salicylazosulfapyridine group (SSZ-G), and L. bulgaricus group (BB-G). In the whole experiment, the mice in all groups were fed for 3 weeks. The mice in the five groups were separately randomized to receive normal saline $(0.1 \mathrm{~mL} / 10 \mathrm{~g})$, LA-XY27 $\left(1 \times 10^{9}\right.$ $\mathrm{CFU} / \mathrm{mL}, 0.1 \mathrm{~mL} / 10 \mathrm{~g})$, sulfasalazine $(20 \mathrm{mg} / \mathrm{kg})$, and L. bulgaricus $\left(1.0 \times 10^{9} \mathrm{CFU} / \mathrm{mL}, 0.1 \mathrm{~mL} / 10 \mathrm{~g}\right)$ by gastric lavage daily for 3 weeks. From the second week, the mice in the control group were fed normal saline, while the mice in the other groups were fed 3\% DSS aqueous solution for 1 week. The body weight, vitality, fecal and anal bleeding of mice were recorded, and the condition of mice was observed after lavage administration on time every day. After 3 weeks of intervention, the mice were fed for 24 hours under the condition of fasting and water. The colon was preserved after the mice were euthanized, and the length and weight were recorded. This study was approved by the Ethics Committee of Chongqing Collaborative Innovation Center for Functional Food (201906019B, Chongqing, China) and followed the national standard of the people's Republic of China (GB/T 35892-2018) laboratory animal-guidelines for ethical review of animal welfare.

\section{The other 4 groups:}

\section{Saline/LA-XY27/ sulfasalazine/Lactobacillus bulgaricus}

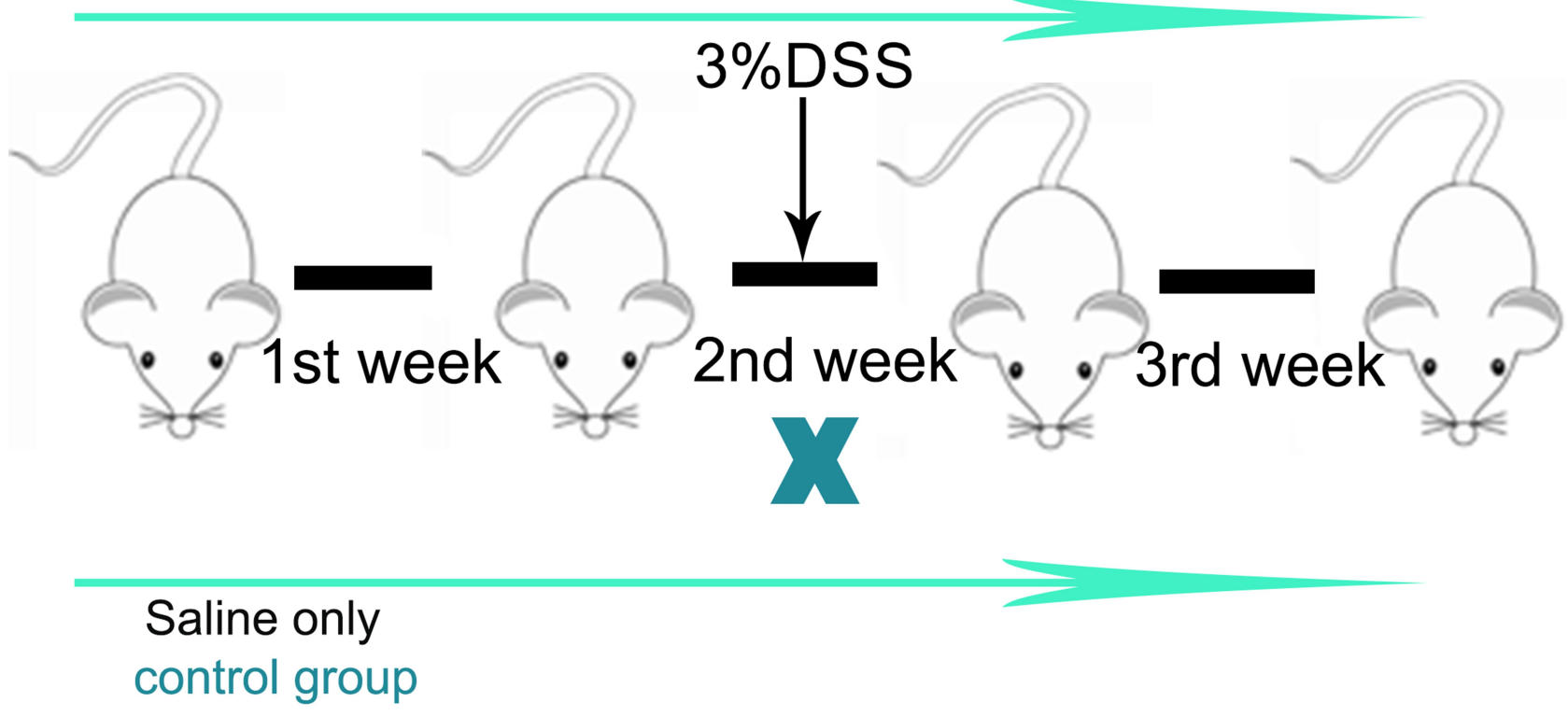

Figure I Illustrative diagram of the experimental process. In addition to the control group, the other four groups were induced by DSS in the second week and maintained for one week. 


\section{Disease Activity Index (DAl) Score of Mice}

The disease activity was evaluated according to the evaluation method of human inflammatory bowel disease (IBD) activity. ${ }^{16}$ According to the blood stool condition and stool characteristics of mice every day, the score was as follows: 0 point for normal stool, 1 point for soft but formed stool, 2 points for unformed stool, and 3 points for loose stool. For bloody stool, 0 point for occult blood negative, 1 point for occult blood positive, 2 points for blood in stool, and 3 points for bloody stool. The disease activity was evaluated by adding the two scores.

\section{Macroscopic Observation of Colon}

The colon tissue with length no more than $0.5 \mathrm{~cm}$ was immersed in $10 \%$ formalin fixation solution for $48 \mathrm{~h}$. The tissue blocks were then trimmed into smaller pieces and then followed by dehydration, embedding in paraffin, sectioning with a thickness of 5-8 $\mu \mathrm{m}$, and staining with hematoxylin and eosin, and finally photographed under a microscope with different magnification (Olympus, Tokyo, Japan).

\section{Detection of Oxidative Stress Factors and Inflammatory Factors in Serum}

Blood samples were collected by enucleating eyeball from mice, then centrifuged at $4000 \mathrm{rpm}$ for $10 \mathrm{~min}$ at $4^{\circ} \mathrm{C}$ to obtain serum. The serum was aspirate and saved standby at $-80^{\circ} \mathrm{C}$ for future use.

The catalase (CAT), myeloperoxidase (MPO), and total superoxide dismutase (T-SOD), and the malondialdehyde (MDA) levels in the serum of mice were detected using the related kits (Nanjing Jiancheng Biological Engineering Research Institute, Nanjing, Jiangsu, China) and enzymelabeling instrument.

The inflammatory factors (TNF- $\alpha$, IFN- $\gamma$, IL-1 $\beta$, IL-6, IL-10, and IL-12) in the serum were detected by using enzyme-linked immunosorbent assays (ELISA kits) (xyA049Rb, XY-R0012c, XY-R0019c, XYA399Mu, xyA058Gu, and XYA133Mu; BioLegend, San Diego, CA, USA) following the manufacturer's protocols.

\section{Detection of Gene Expression in Colon}

Total RNA was extracted from 50 to $100 \mathrm{mg}$ colon tissue of each sample using TRIzol reagent (Invitrogen, Carlsbad, CA, USA) and then the concentration and purity of RNA were detected. RNA was reverse-transcribed into cDNA following the reverse transcription kit instructions (Tiangen Biotech Co., Ltd., Beijing, China). Finally, the target gene was amplified by real-time quantitative polymerase chain reaction using the gene primers listed in Table 1.

\section{Statistical Analysis}

All data were expressed as mean \pm standard deviation. One-way ANOVA analysis of variance was used for data analysis with SPSS 19.0 software. $P<0.05$ indicated a statistically significant difference.

\section{Results}

\section{Body Weight Change and Disease Activity Index (DAI) Score of Mice}

The body weight change and DAI score of mice before and after the end of DSS induction in each group are

Table I Sequences of Gene Primers Used in RT-PCR

\begin{tabular}{|l|l|l|}
\hline Gene Name & Forward & Reverse \\
\hline$\beta$-actin & 5'-ATGGAGCCGGACAGAAAAGC-3' & 5'-TGGGAGGTGTCAACATCTTC-3' \\
EIK-I & 5'-TTGTGTCCTACCCAGAGGTTG-3' & 5'-GCTATGGCCGAGGTTACAGA-3' \\
COX-2 & 5'-TTCCAATCCATGTCAAAACCG-3' & 5'-AGTCCGGGTACAGTCACACT-3' \\
LPS & 5'-GAACAGTATGCAGTGTAAGAG-3' & 5'-GCAGATGCCATAGTTGGTGT-3' \\
Escherichia coli & 5'-GTTAATACCTTTGCTCATTGA-3' & 5'-ACCAGGTACTTAATCCTGTT-3' \\
IL-I2 & 5'-CCTCCACTGTGCTGGTTTTAT-3' & 5'-TCAGCAACATGCTCCAGAAG-3' \\
NF-kB & 5'-TGCGATTCCGCTATAAATGCG-3' & 5'-ACAAGTTCATGTGGATGAGG-3' \\
PI00 & 5'-TGATGGAGGGAACCCAAACTC-3' & 5'-GGATGACCCATTCGGGCTT-3' \\
P53 & 5'-TCACAGCGTCTGTTGACATT-3' & 5'-ACCAAGCTCATTACCCTGAC-3' \\
IKB- $\alpha$ & 5'-CGAGACTTTCGAGGAAATACC-3' & 5'-GTCTGCGTCAAGACTGCTAC-3' \\
TNF- $\alpha$ & 5'-CAGGCGGTGCCTATGTCTC-3' & 5'-CGATCACCCCGAAGTTCAGT-3' \\
IL-I $\beta$ & 5'-GAAATGCCACCTTTTGACAGT-3' & 5'-TGGATGCTCTCATCAGGACA-3' \\
\hline
\end{tabular}

Note: The relative expression of target genes was normalized to the expression level of $\beta$-actin and the level in the DSS-G using the $2^{-\Delta \Delta C T}$ method. 
shown in Figure 2 and Table 2. DSS induction lasted for 7 days from the first day of week 2. Except for the C-G, the weight of mice in the other four groups began to decline on day 3 and day 4. The weight loss in DSS-G, LA-G, and BB-G was the most obvious, followed by the SSZ-G. From the 11th day, that is, 3 days after the end of DSS induction, the weight of mice in the intervention groups began to increase. As of the 14th day, the weight of mice in SSZ-G was the closest to the C-G, followed by the LA$\mathrm{G}$, followed by the DSS-G and BB-G.

On the last day of DSS induction, compared with the C-G $(0.000 \pm 0)$, the DAI score of the other four groups was significantly increased $(\mathrm{P}<0.01)$, the highest in the DSS-G, followed by the other three intervention groups, but there was

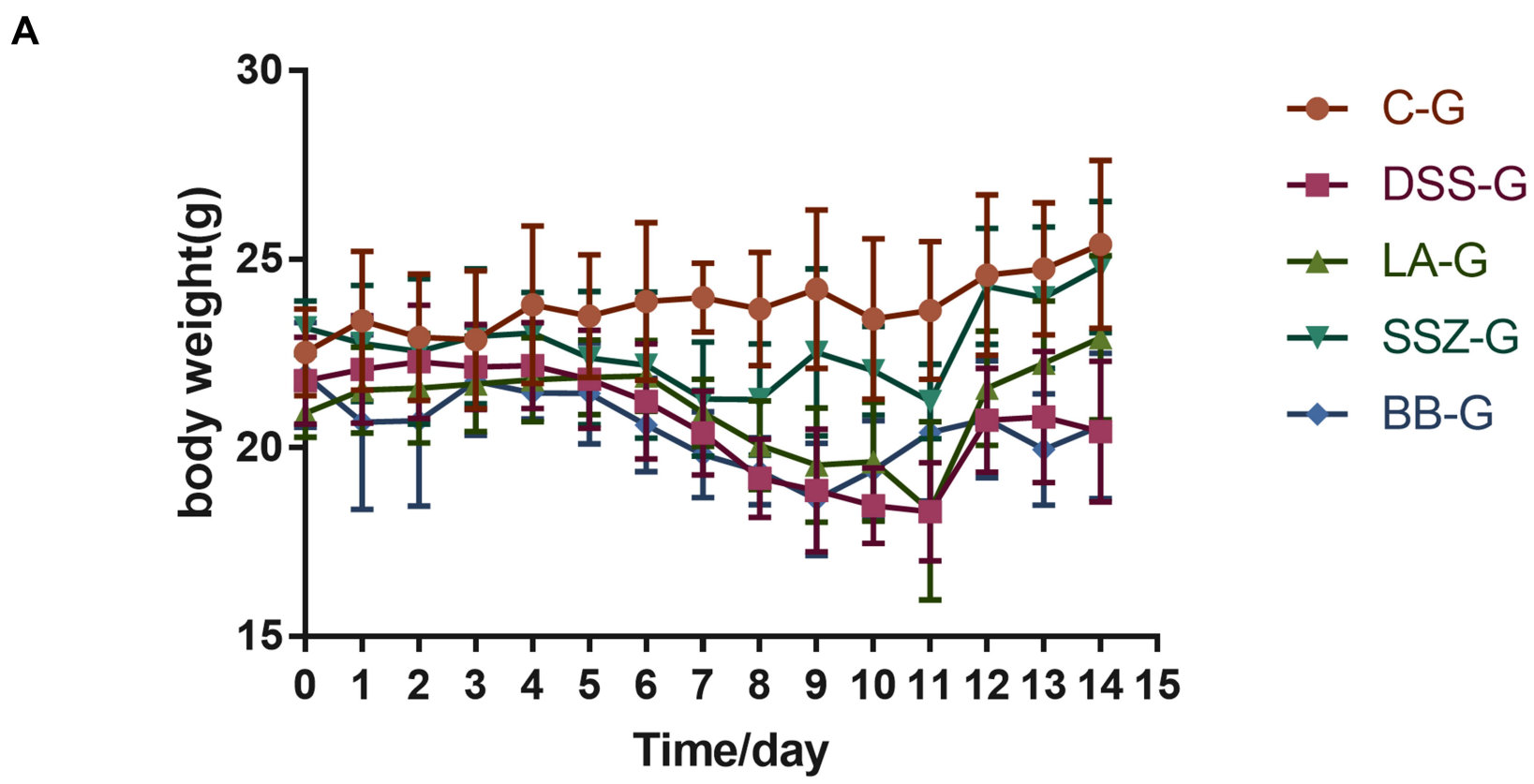

B

C

End of the 2nd week

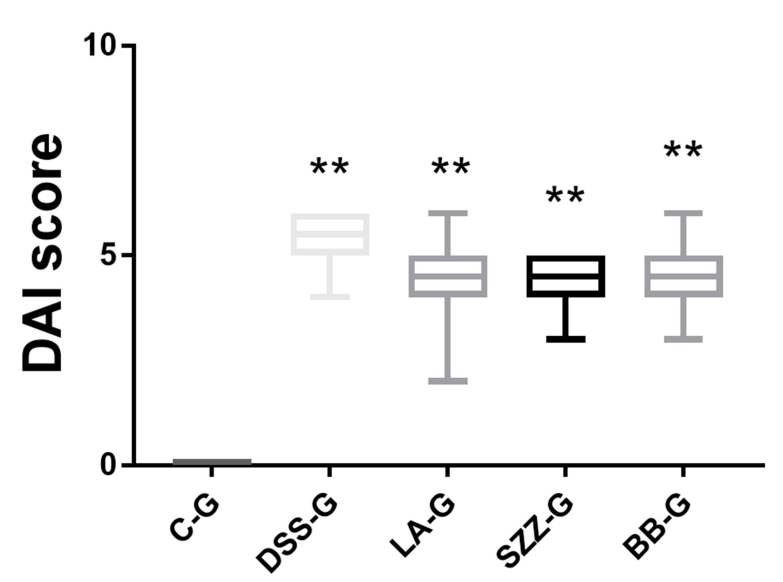

End of the 3rd week

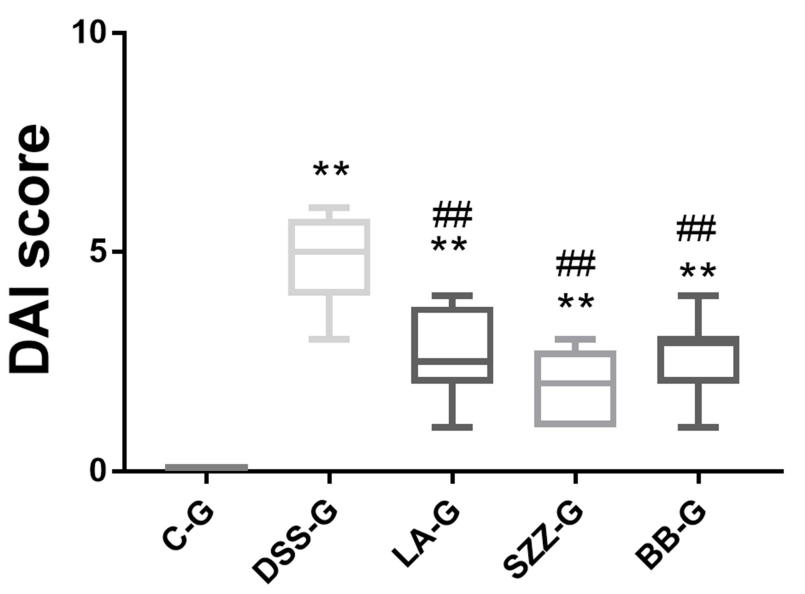

Figure 2 Body weight change curve and DAI score of mice. (A) Weight changes of mice in each group, DSS induction was started on day I and ended on day $7(\mathrm{n}=8)$. (B-C) DAl scores at the end of week 2 (end of DSS induction) (B) and at the end of week 3 (C). All the data were presented as mean \pm SD. $* *$ Means $P<0.01$ compared with the C-G, ${ }^{\#}$ means $\mathrm{p}<0.01$ compared with the DSS-G.

Abbreviations: C-G, control group; DSS-G, DSS-induced group; LA-G, LA-XY27 group; SSZ-G, salicylazosulfapyridine group; BB-G, L. bulgaricus group. 
Table 2 DAI Score of Mice at the End of 2nd and 3rd Week

\begin{tabular}{|l|l|l|}
\hline Group & End of 2nd Week & End of 3rd Week \\
\hline C-G & $0.000 \pm 0$ & $0.000 \pm 0$ \\
DSS-G & $5.375 \pm 0.696^{* *}$ & $4.750 \pm 0.968^{* *}$ \\
LA-G & $4.375 \pm 1.11 I^{* *}$ & $2.625 \pm 0.992^{* * \#}$ \\
SSZ-G & $4.375 \pm 0.696^{* *}$ & $1.875 \pm 0.781^{* * \#}$ \\
BB-G & $4.500 \pm 0.866^{* *}$ & $2.625 \pm 0.857^{* * \#}$ \\
\hline
\end{tabular}

Notes: Values are presented as mean \pm standard deviation $(n=8)$. **Means $\mathrm{p}<$ 0.01 compared with the C-G, ${ }^{\prime \prime}$ means $p<0.01$ compared with the DSS-G.

no statistical difference between the four groups (Figure 2B); after a week of recovery and intervention, compared with the DSS-G, the DAI score of LA-G, SSZ-G, and BB-G were significantly decreased $(\mathrm{P}<0.01$, Figure $2 \mathrm{C})$, SZZ-G decreased the most, followed by LA-G.

\section{Macroscopic Observation of Colon}

As shown in Figure 3 and Table 3, the colon length was noticeably shorter in DSS-G $(6.17 \pm 0.87 \mathrm{~cm})$ than in $\mathrm{C}-\mathrm{G}(7.11 \pm 0.35 \mathrm{~cm})(\mathrm{P}<0.05)$. Although there was no statistical difference, it could be seen from the results that the colonic length in the SSZ-G $(6.27 \pm 0.79 \mathrm{~cm})$ and BB-G $(6.20 \pm 0.90 \mathrm{~cm})$ was longer than that in the DSS-G $(6.17$ $\pm 0.87 \mathrm{~cm})$, but shorter than that in the C-G $(7.11 \pm 0.35 \mathrm{~cm})$ and LA-G $(7.11 \pm 0.62 \mathrm{~cm})$. The colonic length of mice treated with LA-XY27 was longer than that in the DSSG, BB-G, and SSZ-G, indicating that LA-XY27 could prevent colon shortening. The ratio of colon weight to colon length was significantly increased in DSS-treated mice $(0.05 \pm 0.01)$ compared to that of control mice $(0.03$ $\pm 0.01)(\mathrm{P}<0.01)$. The ratio of LA-XY27-treated mice $(0.04$ $\pm 0.01)$ had a significant difference with DSS-treated mice $(0.05 \pm 0.01)(\mathrm{P}<0.01)$, but there was no significant difference compared with the other two treatment groups.

\section{Morphological Observation of Colon Tissue}

As shown in Figure 4, the colonic epithelium of mice in the C-G was intact, no ulcer or hyperplasia was found on the mucosal surface, and the crypt structure was regular and clear without obvious inflammatory infiltration; in the DSS-G, obvious inflammation with a large number of interstitial lymphocytes infiltrated and gathered between the basal layer and mucosal muscle (marked by asterisk), which caused thickening of the basal layer and villous defect (marked by black arrow), and the crypt showed structural changes such as shortening, branching, and curling (marked by yellow arrow).
Compared with the DSS-G, the inflammatory reaction of the three intervention groups was reduced, but the effect of LA-G was the best, which was the closest to that of C-G. The crypt structure of LA-G tended to be normal, with only slight lymphatic infiltration in the basement layer. In SSZ-G, there were a small number of lymphocyte infiltration and a few crypt abnormalities, while the effect of BB-G is not very good, with multiple lymphatic infiltration and villus defects.

\section{Levels of Oxidative Stress Factors in Serum}

Table 4 and Figure 5 shows that the CAT and T-SOD in the DSS-G (152.96 \pm 53.9 and 64.79 \pm 8.51$)$ were significantly lower than that in the C-G $(589.33 \pm 61.9$ and $91.88 \pm 5.12)$ $(\mathrm{P}<0.01)$, while MDA and MPO were higher in DSS-G $(10.58 \pm 2.95$ and $830.04 \pm 71.1)$ than that in $\mathrm{C}-\mathrm{G}(5.50 \pm 2.69$ and 786.62 \pm 60.5$)$. The CAT and T-SOD levels increased both in LA-G (536.58 \pm 68.1 and 89.86 \pm 2.15$)$ and SSZ-G (477.68 \pm 103.1 and $89.96 \pm 6.52)$ compared to DSS-G $(P<0.05)$. The MDA and MPO contents reduced significantly in LA-G (5.59 \pm 2.59 and $794.64 \pm 51.9)$ and SSZ-G (6.59 \pm 3.69 and 795.22 $\pm 55.5)$ and BB-G $(6.81 \pm 2.67$ and $797.34 \pm 49.0)(\mathrm{P}<0.01)$. While there was no significant effect on CAT in BB-G. In conclusion, the data of LA-G were closer to that of $\mathrm{C}-\mathrm{G}$, which confirming that the effect of LA-XY27 was better.

\section{Levels of Inflammatory Cytokines in Serum}

Table 5 and Figure 6 shows that the levels of IFN- $\gamma$, IL- $1 \beta$, IL-6, IL-12, and TNF- $\alpha$ in the serum were the lowest in the $\mathrm{C}-\mathrm{G}$ among all the groups, while the levels of IL-10 were the highest, in contrast, the aforementioned indicators followed the opposite trends in the DSS-G, there was significant difference between the two groups $(\mathrm{P}<0.01)$. The concentrations of IFN- $\gamma$, IL-10, IL-12, IL-6, and TNF- $\alpha$ improved significantly in the three intervention groups $(\mathrm{P}<0.05)$, especially there was no significant difference in IFN, TNF, and IL-12 between LA-G and C-G.

\section{Gene Expression of the Colonic Tissue}

As shown in Table 6 and Figure 7, the relative expression levels of EIK-1, IL-12, IL-1 $\beta$, COX-2, TNF- $\alpha$, E. coli, LPS, and p100 genes were higher while the relative expression levels of $\mathrm{ZO}-1$, NF- $\kappa \mathrm{B}, \mathrm{p} 53$, and IKB- $\alpha$ genes were lower in the DSS-G compared with the C-G $(\mathrm{P}<0.01)$, which were consistent with previously reported levels in serum. Although there were differences 
A

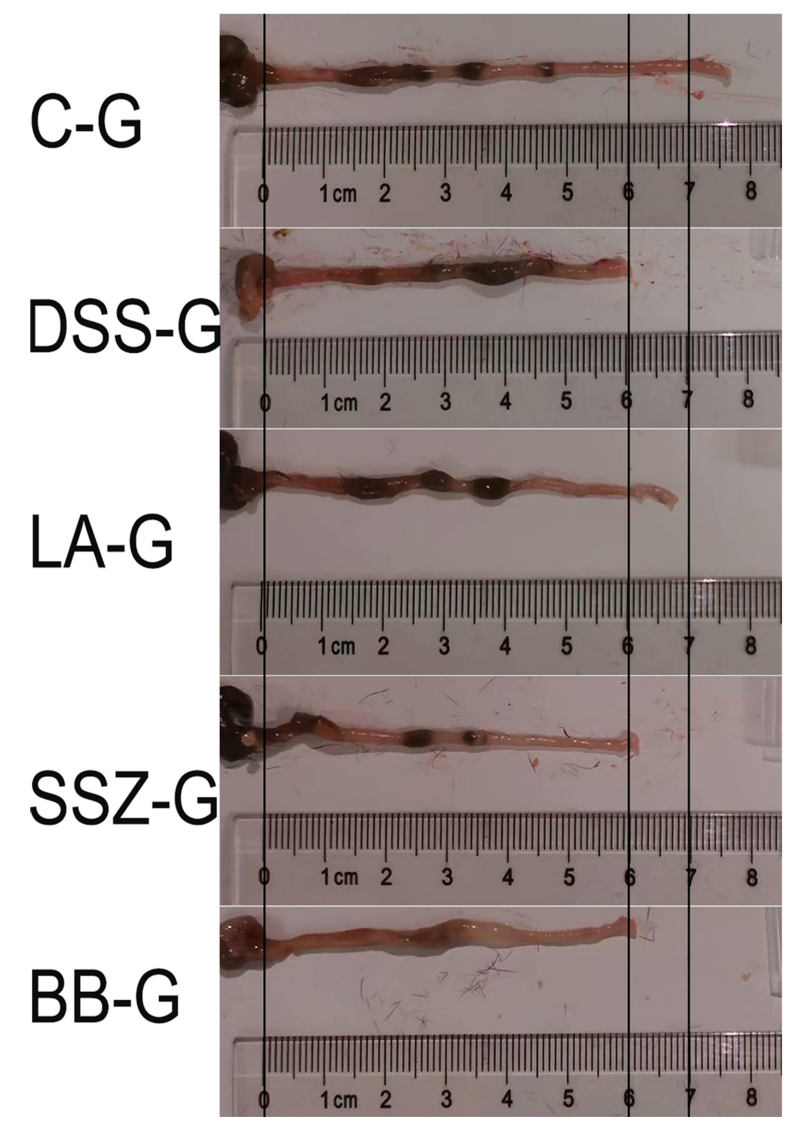

B

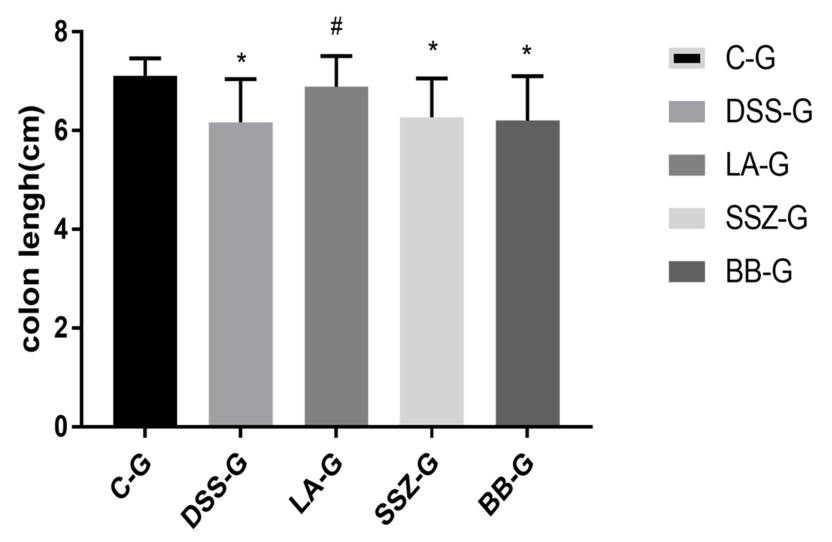

C

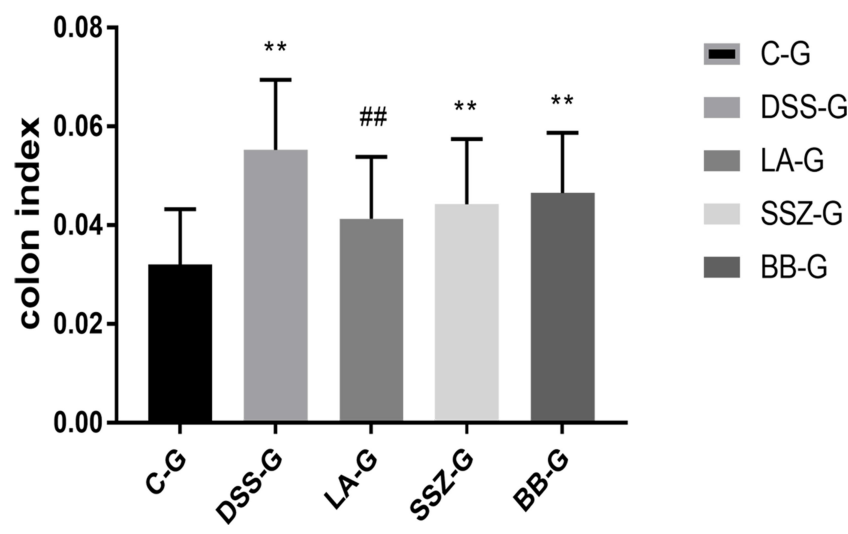

Figure 3 Colon length and colon index in each group. (A-B) Representative images and bar chart of colon length in each group $(n=8)$. $(\mathbf{C})$ colon index in each group ( $n=8)$. All the data were presented as mean \pm SD in B and C. * and ** means $p<0.05$ and $p<0.01$ respectively compared with the C-G; ${ }^{*}$ and ${ }^{\# \#}$ means $p<0.05$ and $p<0.01$ respectively compared compared with the DSS-G.

Abbreviations: C-G, control group; DSS-G, DSS-induced group; LA-G, LA-XY27 group; SSZ-G, salicylazosulfapyridine group; BB-G, L. bulgaricus group.

in LPS, EIK-1, p100, TNF- $\alpha$ between all the groups, the change of $E$. coli, IL-12 NF- $\kappa \mathrm{B}, \mathrm{ZO}-1$ and IL-1 $\beta$ were more obvious. In general, the relative expression levels of EIK-1, IL-12, IL-1 $\beta$, TNF- $\alpha$, E. coli, LPS, p100, and COX-2 genes were significantly lower in the LA-G than

Table 3 Colonic Length and the Ratio of Colonic Weight to Colonic Length

\begin{tabular}{|l|l|l|}
\hline Group & $\begin{array}{l}\text { Colonic Length } \\
(\mathbf{c m})\end{array}$ & $\begin{array}{l}\text { Colonic Weight/Colonic Length } \\
(\mathbf{g} / \mathbf{c m})\end{array}$ \\
\hline C-G & $7.11 \pm 0.35$ & $0.03 \pm 0.01$ \\
DSS-G & $6.17 \pm 0.87^{*}$ & $0.05 \pm 0.01^{* *}$ \\
LA-G & $6.89 \pm 0.62^{\#}$ & $0.04 \pm 0.01^{\# \#}$ \\
SSZ-G & $6.27 \pm 0.79^{*}$ & $0.04 \pm 0.01^{* *}$ \\
BB-G & $6.20 \pm 0.90^{*}$ & $0.04 \pm 0.01^{* *}$ \\
\hline
\end{tabular}

Notes: Values are presented as mean \pm standard deviation $(n=8)$. *Means $p<0.05$ compared with the C-G, ${ }^{*}$ means $p<0.05$ compared with the DSS-G. **Means $p<0.01$ compared with the C-G, "\#means $p<0.01$ compared with the DSS-G. in the DSS-G, while the relative expression levels of ZO$1, \mathrm{NF}-\kappa \mathrm{B}, \mathrm{p} 53$, and IKB- $\alpha$ genes significantly increased and were closer to those in the $\mathrm{C}-\mathrm{G}$ compared with the other two treatment groups (SZZ-G and BB-G), suggesting that LA-XY27 can adjust the levels of inflammatory factors more effectively.

\section{Discussion}

In this study, the preventive and regulatory effects of LAXY27 were verified by using the DSS-induced model. DSS induces superficial ulceration, mucosal damage, diarrhea, rectal bleeding, and loss of body weight, this model is elementary and reproducible and its clinical symptoms are similar to ulcerative colitis. ${ }^{17,18}$

The results of DAI disease score scale showed that LAXY27 had a good relieving effect on hematochezia and alleviate the weight loss caused by 3\% DSS feeding. Due to colonic edema, the weight increased, the length shortened, 


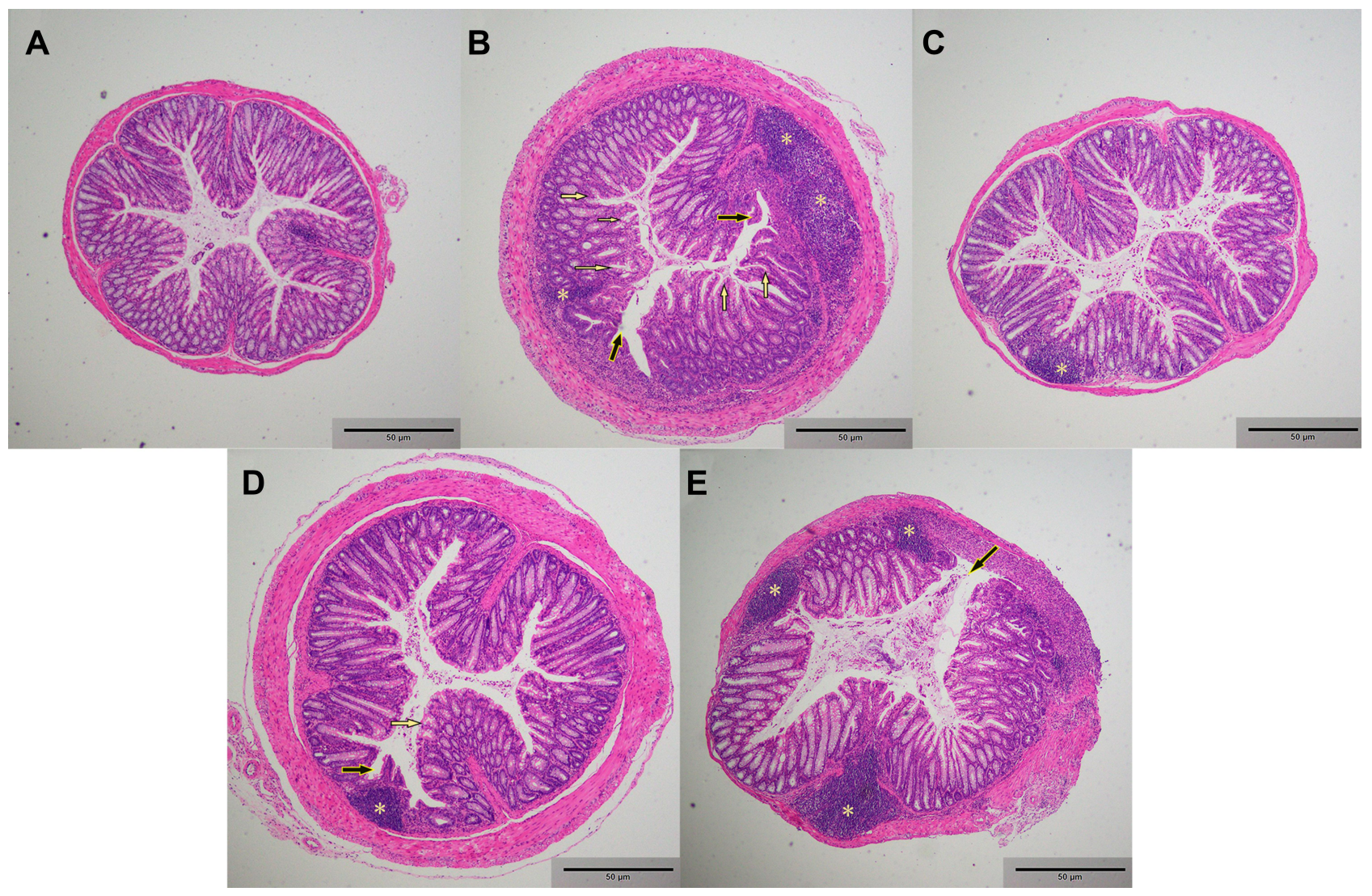

Figure 4 Morphological observation of colon. The asterisk, black arrow and yellow arrow in the picture respectively indicates interstitial lymphocyte infiltration, villous defect, and the crypt structural changes. (A): C-G, (B): DSS-G, (C): LA-G, (D): SSZ-G, (E): BB-G. Scale bar: $50 \mu \mathrm{m}$.

and the ratio of colonic weight to colonic length was higher in the DSS model mice than that in normal mice. ${ }^{1,19,20}$ The colonic length was significantly longer in the LA-G than in the DSS-G, and the ratio of colonic weight/length was smaller in the LA-G than in the DSS-G. The pathological sections of the colon tissue further showed that LA-XY27 treatment significantly reduced the infiltration and proliferation of lymphocytes caused by inflammation, which preliminarily proved the anti-inflammatory effect of LA-XY27 on DSSinduced colitis. In this study, we observed treatment with LAXY27 could not only relieve shortened colon and reduce the ratio of colonic weight/length but also prevented mucosal damage, and remitted inflammatory cells infiltration. Therefore, we speculated that LA-XY27 may have a good effect on the intestinal mucosa.

Colitis leads to a rapid increase in the contents of free radicals such as reactive oxygen species (ROS) and reactive nitrogen species (RNS), further aggravating the damage and toxicity in the colon tissue, followed by a significant increase in the contents of peroxidation products MDA and MPO and a decrease in the levels of antioxidants SOD and CAT. ${ }^{21,22}$ Therefore, the antioxidant

Table 4 Determination of Oxidation Indexes in the Serum

\begin{tabular}{|l|l|l|l|l|}
\hline Group & CAT $(\mathbf{U} / \mathbf{m L})$ & T-SOD $(\mathbf{U} / \mathbf{m L})$ & MDA $(\mathbf{n m L} / \mathbf{m L})$ & MPO(U/mL) \\
\hline C-G & $589.33 \pm 61.9^{\# \#}$ & $91.88 \pm 5.12^{\#}$ & $5.50 \pm 2.69^{\# \#}$ & $786.62 \pm 60.5^{\# \#}$ \\
DSS-G & $152.96 \pm 53.9^{* *}$ & $64.79 \pm 8.51^{*}$ & $10.58 \pm 2.95^{* *}$ & $830.04 \pm 71.1^{* *}$ \\
LA-G & $536.58 \pm 68.1^{* * \#}$ & $89.86 \pm 2.15^{* \#}$ & $5.59 \pm 2.59^{\# \#}$ & $794.64 \pm 51.9^{\# \#}$ \\
SSZ-G & $477.68 \pm 103.1^{* * \#}$ & $89.96 \pm 6.52^{* \#}$ & $6.59 \pm 3.69^{\#}$ & $795.22 \pm 55.5^{\# \#}$ \\
BB-G & $219.69 \pm 86.6^{* *}$ & $87.99 \pm 3.34^{* \#}$ & $6.81 \pm 2.67^{* \#}$ & $797.34 \pm 49.0^{* \#}$ \\
\hline
\end{tabular}

Notes: Values are presented as mean \pm standard deviation $(n=8)$. *Means $p<0.05$ compared with the C-G, ${ }^{*}$ means $p<0.05$ compared with the DSS-G. **Means $p<0.01$ compared with the C-G, ${ }^{\#}$ means $\mathrm{p}<0.01$ compared with the DSS-G. 

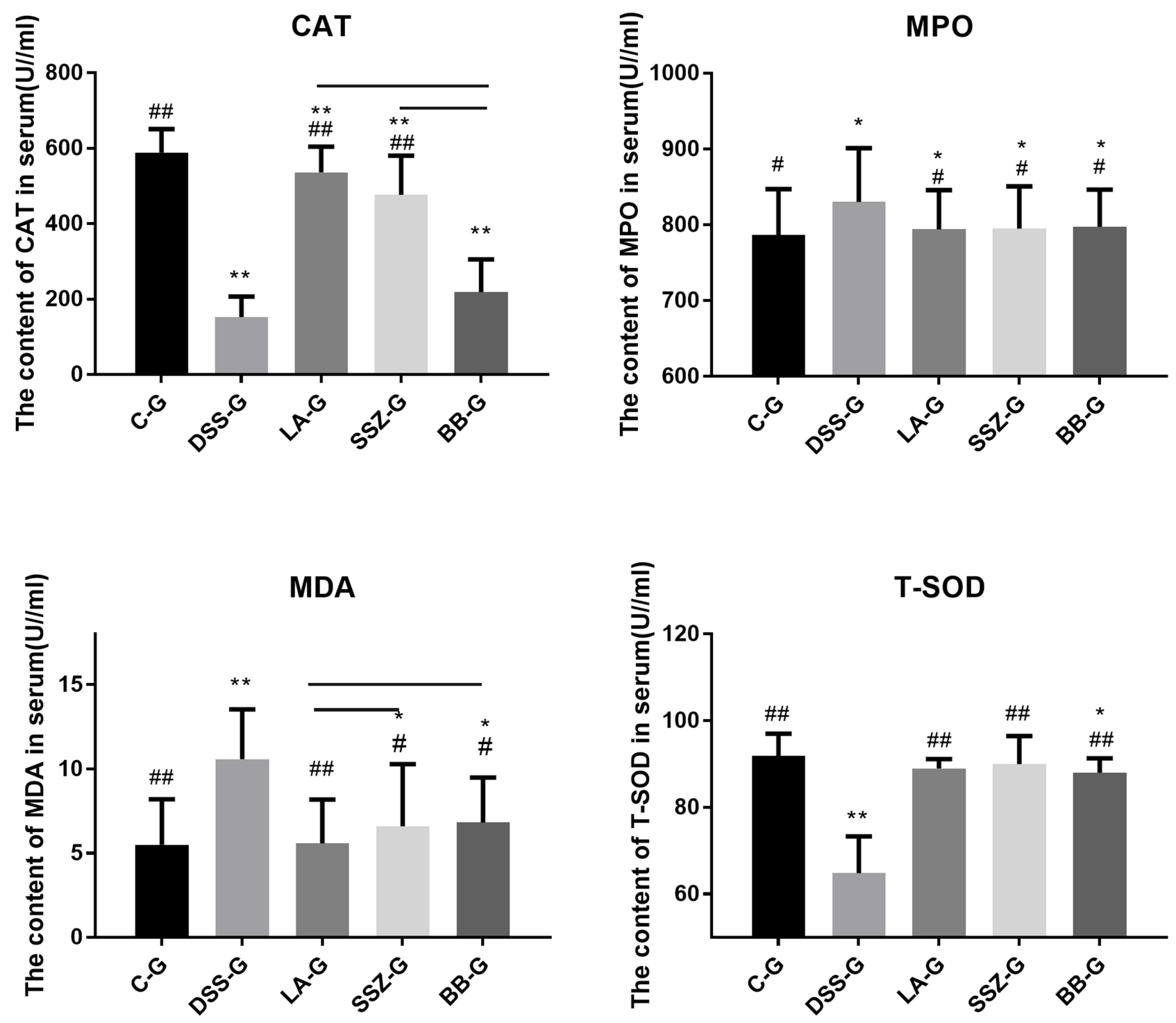

Figure 5 Oxidative stress factors in the serum. All the data were presented as mean \pm SD ( $n=8)$. *Represents a significant difference compared with the C-G, ${ }^{*}$ represents a significant difference compared with the DSS-G, Horizontal lines were used to indicate whether there was a statistical difference between the three intervention groups; $*$ or ${ }^{\#}$ means $p<0.05$, ** or ${ }^{\# \#}$ means $p<0.01$.

Abbreviations: C-G, control group; DSS-G, DSS-induced group; LA-G, LA-XY27 group; SSZ-G, salicylazosulfapyridine group; BB-G, L. bulgaricus group.

and anti-inflammatory effects of LA-XY27 were verified by detecting the related oxidation indexes and inflammatory factors in serum and colon tissue. CAT is a marker enzyme of peroxisomes, which exists in the peroxides of cells in various tissues of all known animals. CAT is one of the key enzymes in the biological defense system with

Table 5 Serum Inflammatory Cytokines

\begin{tabular}{|l|l|l|l|l|l|l|}
\hline Group & IFN- $\gamma(\mathbf{n g} / \mathbf{L})$ & IL-I $\beta$ (ng/L) & IL-6 (pg/mL) & IL-I0 (pg/mL) & TNF- $\alpha$ (ng/L) & IL-I2 (ng/L) \\
\hline C-G & $5.5681 \pm 1.17^{\# \#}$ & $7.0394 \pm 1.16^{\# \#}$ & $5.3286 \pm 0.92^{\# \#}$ & $8.5216 \pm 1.21^{\# \#}$ & $1.4822 \pm 1.04^{\# \#}$ & $4.8204 \pm 1.79^{\# \#}$ \\
DSS-G & $7.6742 \pm 1.21^{* *}$ & $9.2506 \pm 1.02^{* *}$ & $8.5388 \pm 1.46^{* *}$ & $4.2114 \pm 1.39^{* *}$ & $3.8984 \pm 2.08^{* *}$ & $7.7288 \pm 1.65^{* *}$ \\
LA-G & $5.6702 \pm 1.63^{\# \#}$ & $8.0422 \pm 1.88^{* \#}$ & $6.2290 \pm 01.32^{* \#}$ & $6.7188 \pm 1.10^{\# \#}$ & $1.7868 \pm 2.03^{\# \#}$ & $5.3218 \pm 1.97^{\# \#}$ \\
SSZ-G & $6.6724 \pm 1.18^{* \#}$ & $8.6497 \pm 1.35^{* \#}$ & $7.6342 \pm 1.11^{*}$ & $5.8170 \pm 1.50^{* \# \#}$ & $1.8920 \pm 1.72^{\# \#}$ & $5.8230 \pm 1.57^{\# \#}$ \\
BB-G & $6.0730 \pm 1.78^{\#}$ & $8.8499 \pm 2.21^{* \#}$ & $7.3326 \pm 1.88^{*}$ & $5.5178 \pm 1.19^{* \# \#}$ & $2.3884 \pm 1.14^{* \# \#}$ & $6.4224 \pm 1.01^{* \#}$ \\
\hline
\end{tabular}

Notes: Values are presented as mean \pm standard deviation $(n=8)$. *Means $p<0.05$ compared with the C-G, ${ }^{\#}$ means $p<0.05$ compared with the DSS-G. **Means $p<0.01$ compared with the C-G, "\#means $\mathrm{p}<0.01$ compared with the DSS-G. 

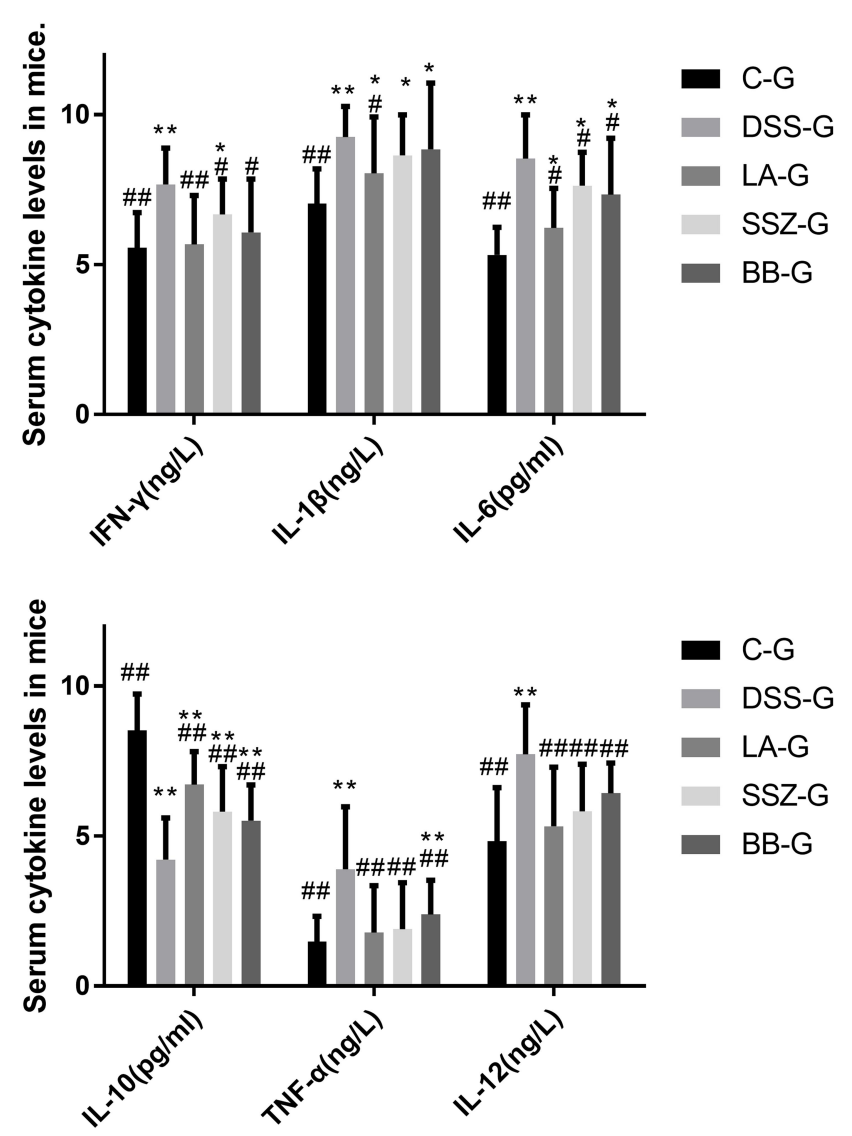

Figure 6 Inflammatory factors in serum. All the data were presented as mean \pm SD $(n=8)$. *Represents a significant difference compared with the C-G, ${ }^{*}$ represents a significant difference compared with the DSS-G, *or ${ }^{\#}$ means $\mathrm{p}<0.05$, ** or ${ }^{\# \#}$ means $p<0.01$.

Abbreviations: C-G, control group; DSS-G, DSS-induced group; LA-G, LA-XY27 group; SSZ-G, salicylazosulfapyridine group; BB-G, L. bulgaricus group.

strong antioxidant function. It can decompose hydrogen peroxide into water and oxygen out of the body, reduce the concentration and toxicity of hydrogen peroxide, and protect cells and tissues from oxidative stress. MPO is a kind of heme protein, which is released by the accumulation and dispersion of neutrophils caused by inflammatory stimulation. The significant increase in MPO level indicates the inflammatory response. ${ }^{4}$ The decrease in MPO activity represents the decrease in neutrophil aggregation in inflamed tissues. In normal cells, SOD protects the body from tissue damage caused by free radicals, and inhibiting the decrease in the SOD level in the body can effectively alleviate the injury of the body. ${ }^{23}$ The aforementioned indexes are biomarkers of oxidative stress. In this study, the levels of CAT and T-SOD in the serum increased and the levels of MDA and MPO effectively reduced in all intervention groups, while the effect of L. acidophilus XY27 was better than that of L. bulgaricus and salicylazosulfapyridine.

Inflammatory mediators, especially cytokines, mediate immune cells to regulate inflammatory response and balance intestinal mucosal barrier function. Many pieces of literature have reported that probiotics for intestinal flora can improve intestinal barrier function by regulating inflammatory factors. ${ }^{23-25}$ In the present study, LA-XY27 treatment could effectively reduce the levels of many proinflammatory cytokines, including IFN- $\gamma$, IL-1 $\beta$, IL-6, TNF- $\alpha$, and IL-12, in the serum, and increase the levels of anti-inflammatory cytokine IL-10. This result was further verified by gene expression in the colon of mice with colitis. In addition, the relative expression levels of COX-2, EIK-1, E. coli, LPS, and p100 genes in mice with colitis treated with LA-XY27 were significantly lower than those in the model group, while the relative expression levels of protective factors ZO-1, NF- $\mathrm{B}$, p53, and

Table 6 Gene Expression in the Colon Tissue

\begin{tabular}{|c|c|c|c|c|c|}
\hline Gene Name & C-G & DSS-G & LA-G & SSZ-G & BB-G \\
\hline EIK-I & $0.8561 \pm 0.086^{\#}$ & $1 \pm 0$ ** & $0.9384 \pm 0.077^{\mathrm{\# \#}}$ & $0.9644 \pm 0.050^{* * \# \#}$ & $0.9643 \pm 0.022^{\# \#}$ \\
\hline COX-2 & $0.8073 \pm 0.014^{\# \#}$ & $1 \pm 0^{* *}$ & $0.9140 \pm 0.365^{* * \# \#}$ & $0.9876 \pm 0.068 * *$ & $0.9591 \pm 0.0494^{* * \# \#}$ \\
\hline LPS & $0.9020 \pm 0.074^{\# \#}$ & $1 \pm 0$ ** & $0.9453 \pm 0.0 .133^{* * \# \#}$ & $0.9846 \pm 0.017^{* * \#}$ & $0.9568 \pm 0.054^{* *}$ \\
\hline Escherichia coli & $0.1428 \pm 0.016^{\# \#}$ & $1 \pm 0$ ** & $0.2339 \pm 0.023^{* * \# \#}$ & $0.2798 \pm 0.012^{* * \# \#}$ & $0.2943 \pm 0.198^{\# \#}$ \\
\hline IL-I2 & $0.4902 \pm 0.035^{\# \#}$ & $\mathrm{I} \pm 0 * *$ & $0.6046 \pm 0.099^{* * \#}$ & $0.7491 \pm 0.055^{* * \#}$ & $0.7926 \pm 0.042^{\# \#}$ \\
\hline$N F-\kappa B$ & $42.97 \pm 13.34^{\# \#}$ & $1 \pm 0$ ** & $19.906 \pm 4.760^{* * \# \#}$ & $2.7016 \pm 0.648^{* * \# \#}$ & $1.1821 \pm 0.073^{* *}$ \\
\hline pl00 & $0.9703 \pm 0.065^{\#}$ & $1 \pm 0$ ** & $0.9921 \pm 0.028^{* \#}$ & $0.9987 \pm 0.057^{*}$ & $0.9940 \pm 0.038^{*}$ \\
\hline p53 & $1.1807 \pm 0.052^{\# \#}$ & $1 \pm 0$ ** & $1.0794 \pm 0.110^{* * \# \#}$ & $1.0405 \pm 0.112^{* * \# \#}$ & $1.0619 \pm 0.014^{\# \#}$ \\
\hline $\mathrm{lkB}-\alpha$ & $10.2913 \pm 0.503^{\# \#}$ & $1 \pm 0.92 * *$ & $2.5118 \pm 0.044^{* * \# \#}$ & $1.2174 \pm 0.110^{* *}$ & $1.8500 \pm 0.06^{\# \#}$ \\
\hline TNF- $\alpha$ & $0.9241 \pm 0.164^{\# \#}$ & $I \pm 0 * *$ & $0.9644 \pm 0.041^{* * \# \#}$ & $0.9792 \pm 0.158^{* * \# \#}$ & $0.9763 \pm 0.110^{\# \#}$ \\
\hline IL-I $\beta$ & $0.3705 \pm 0.404^{\# \#}$ & $I \pm 0$ ** & $0.6221 \pm 0.172^{* * \# \#}$ & $0.7873 \pm 0.182^{* * \#}$ & $0.7835 \pm 0.020^{\text {\#\# }}$ \\
\hline ZO-I & $2.7308 \pm 0.346^{\# \#}$ & $\mathrm{I} \pm 0^{* *}$ & $1.9520 \pm 0.658^{* * \# \#}$ & $1.2500 \pm 0.1637^{* * \# \#}$ & $1.5747 \pm 0.060^{\# \#}$ \\
\hline
\end{tabular}

Notes: Values are presented as mean \pm standard deviation $(n=8)$. *Means $p<0.05$ compared with the C-G, ${ }^{\#}$ means $p<0.05$ compared with the DSS-G. $* *$ Means $p<0.01$ compared with the C-G, "means $\mathrm{p}<0.01$ compared with the DSS-G. 

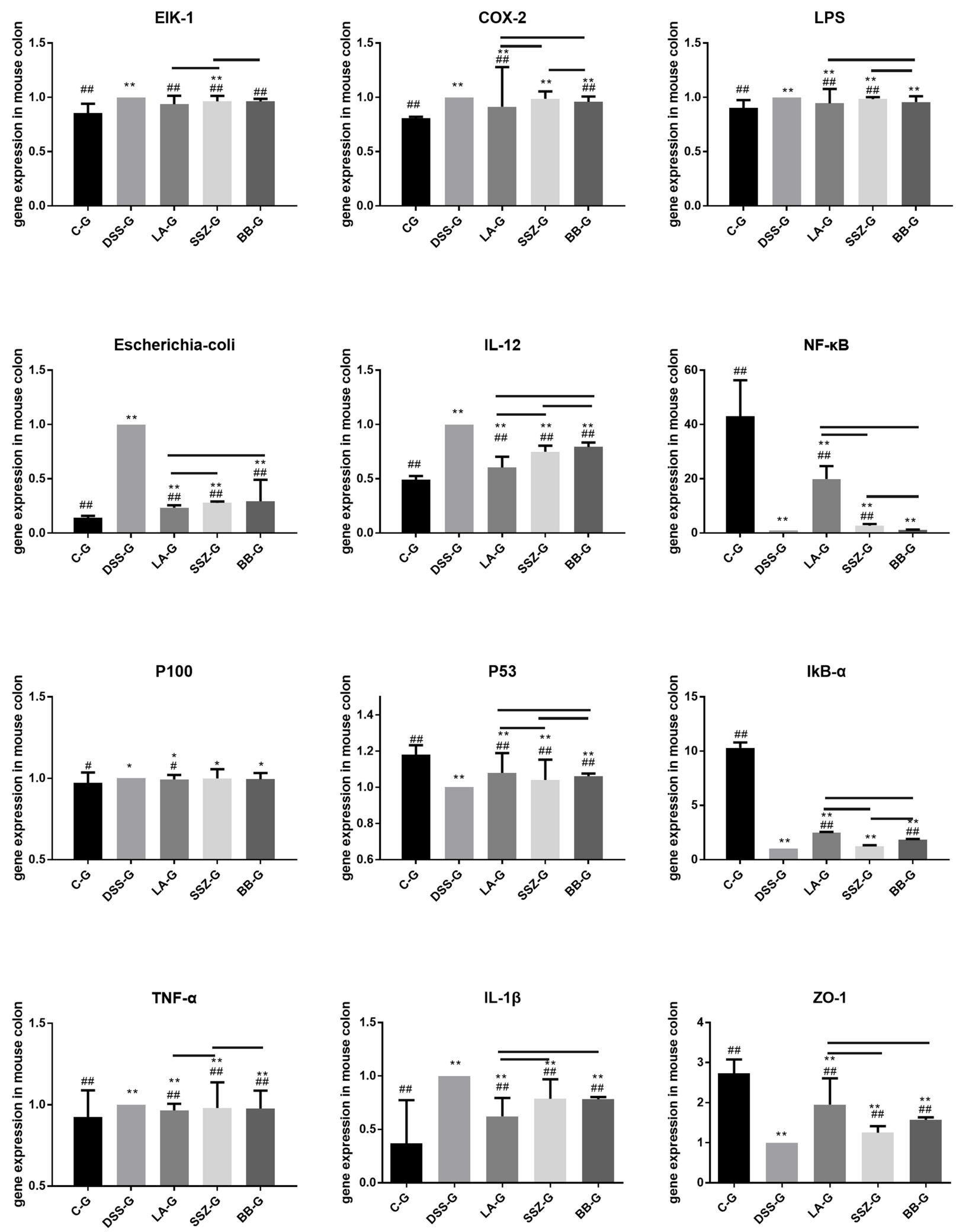

Figure 7 Gene expression in the colon. All the data were presented as mean $\pm S D(n=8)$. *Represents a significant difference compared with the C-G, ${ }^{\#}$ represents a significant difference compared with the DSS-G, Horizontal lines were used to indicate whether there was a statistical difference between the three intervention groups; ${ }^{*}$ or ${ }^{\#}$ means $p<0.05$, ** or ${ }^{\#}$ means $p<0.01$.

Abbreviations: C-G, control group; DSS-G, DSS-induced group; LA-G, LA-XY27 group; SSZ-G, salicylazosulfapyridine group; BB-G, L. bulgaricus group. 
IKB- $\alpha$ significantly increased. The decrease in the expression of the COX-2 gene also downregulated the expression of pro-inflammatory factors, inhibited inflammatory response, reduced intestinal inflammatory response and immune response, blocked inflammatory factors, and activated the NF-KB pathway, which was important in inhibiting the local inflammatory response and treating UC. LPS is a potential candidate for endotoxin antagonists. ${ }^{26}$ Recent studies revealed that LPS from some kind of bacteria is not only the inducer of pro-inflammatory cytokines, such as $\mathrm{TNF}-\alpha$, but also a competitive endotoxin antagonist with a universal type of action. ${ }^{27}$

In this experiment, the effect of LA-XY27 seems to be better than that of L. bulgaricus, which may be due to the species specificity. Some authors conducted a metaanalysis on the effects of different kinds of probiotics on UC by analyzing 27 trials, demonstrating that probiotics were generally effective in treating $\mathrm{CD}$ and $\mathrm{UC}{ }^{23,28}$ Lactobacillus probiotics are more effective against UC. ${ }^{10}$ Although the effect is positive, the effective strains are still very limited, and the clinical efficacy and evidence are not sufficient. ${ }^{29}$ The strains in this experiment were isolated and purified from herdsmen in Xinyuan County, Northwest Xinjiang Uygur Autonomous region, where the climate and geographical conditions were unique. For a long time, traditional yoghurt produced by herdsmen has a good health-care effect. Our preliminary experiments also proved that the Lactobacillus fermentum Suo isolated from yak yoghurt of Hongyuan grassland (Ngawa Tibetan and Qiang Autonomous Prefecture, Aba, Sichuan, China) houseland attenuates $\mathrm{HCl} /$ Ethanol-induced gastric injury in mice through its antioxidant effects. ${ }^{30}$ Another Lactobacillus fermentum HY01 (LF-HY01) isolated from traditional fermented yak yoghurt of Hongyuan has been proven to have prevented effects on dextran sulfate sodium-induced colitis in mice. ${ }^{31}$.

The results suggested that LA-XY27 prevented and reduced the symptoms of colitis mainly by downregulating the levels of pro-inflammatory factors, enhancing antiinflammatory factors and antioxidant capacity, and restoring intestinal barrier function. The effective mechanism of LA-XY27 is worth exploration. However, meta-analyses provided limited evidence for using $L$. acidophilus to treat acute gastroenteritis in children. Therefore, more largescale, high-quality clinical trials should be conducted to verify the clinical application feasibility of the strains. ${ }^{32,33}$ The findings of this in vitro study might provide the basis and reference for future clinical research.

\section{Conclusions}

L. acidophilus XY27 had a better effect compared with L. bulgaricus and salicylazosulfapyridine in preventing DSS-induced colitis and relieving the symptoms of colitis in mice in this study. L. acidophilus XY27 exerted its effect mainly by enhancing the antioxidant capacity, repairing the intestinal barrier, and regulating the expression of inflammation-related genes and the secretion of inflammatory factors.

\section{Acknowledgment}

This research was funded by Chongqing University Innovation Research Group Project (CXQTP20033), the Science and Technology Project of Chongqing Education Commission (KJQN202001604) and the Research Project of Chongqing University of Education (KY201920C), China.

\section{Disclosure}

The authors report no conflicts of interest in this work.

\section{References}

1. Saniabadi AR, Tanaka T, Ohmori T, Sawada K, Yamamoto T, Hanai $\mathrm{H}$. Treating inflammatory bowel disease by adsorptive leucocytapheresis: a desire to treat without drugs. World J Gastroenterol. 2014;20:9699-9715. doi:10.3748/wjg.v20.i29.9699

2. Farooq SM, Hou Y, Li H, et al. Disruption of GPR35 Exacerbates Dextran Sulfate Sodium-Induced Colitis in Mice. Dig Dis Sci. 2018;63(11):2910-2922. doi:10.1007/s10620-018-5216-z

3. Weldon MJ, Maxwell JD. Lymphocyte and macrophage interleukin receptors in inflammatory bowel disease: a more selective target for therapy? Gut. 1994;35(7):867-871. doi:10.1136/gut.35.7.867

4. Kolgazi M, Uslu U, Yuksel M, Velioglu-Ogunc A, Ercan F, Alican I. The role of cholinergic anti-inflammatory pathway in acetic acid-induced colonic inflammation in the rat. Chem Biol Interact. 2013;205(1):72-80. doi:10.1016/j.cbi.2013.06.009

5. Sun M, Liu Y, Song Y, et al. The ameliorative effect of Lactobacillus plantarum -12 on DSS-induced murine colitis. Food Funct. 2020;11 (6):5205-5222. doi:10.1039/d0fo00007h

6. Mital BK, Garg SK. Anticarcinogenic, hypocholesterolemic, and antagonistic activities of Lactobacillus acidophilus. Crit Rev Microbiol. 1995;21:175-214. doi:10.3109/10408419509113540

7. Zhang J, Li Q, Wei Y, et al. Process Design of the Antioxidant Shuidouchi and Its Effect on Preventing Dextran Sulfate Sodium (DSS)-Induced Colitis in Mice via Antioxidant Activity. App Sci. 2018;9(1):5. doi:10.3390/app9010005

8. Yi R, Peng P, Zhang J, et al. Lactobacillus plantarum CQPC02-Fermented Soybean Milk Improves Loperamide-Induced Constipation in Mice. J Med Food. 2019;22(12):1208-1221. doi:10.1089/jmf.2019.4467

9. Koretz RL. Probiotics in Gastroenterology: how Pro Is the Evidence in Adults? Am J Gastroenterol. 2018;113(8):1125-1136. doi:10.1038/ s41395-018-0138-0

10. Meijer BJ, Dieleman LA. Probiotics in the treatment of human inflammatory bowel diseases. J Clin Gastroenterol. 2011;45(Suppl): S139-S144. doi:10.1097/MCG.0b013e31822103f7 
11. Ganji-Arjenaki M, Rafieian-Kopaei M. Probiotics are a good choice in remission of inflammatory bowel diseases: A meta analysis and systematic review. J Cell Physiol. 2018;233(3):2091-2103. doi: $10.1002 /$ jcp. 25911

12. Bull M, Plummer S, Marchesi J, Mahenthiralingam E. The life history of Lactobacillus acidophilus as a probiotic: a tale of revisionary taxonomy, misidentification and commercial success. FEMS Microbiol Lett. 2013;349(2):77-87. doi:10.1111/1574-6968.12293

13. McFarland LV, Evans CT, Goldstein EJC. Strain-Specificity and Disease-Specificity of Probiotic Efficacy: A Systematic Review and Meta-Analysis. Front Med. 2018;5:124. doi:10.3389/ fmed.2018.00124

14. Saxelin M, Tynkkynen S, Mattila-Sandholm T, de Vos WM. Probiotic and other functional microbes: from markets to mechanisms. Curr Opin Biotechnol. 2005;16(2):204-211. doi:10.1016/j.copbio.2005.02.003

15. Goldstein EJC, Tyrrell KL, Citron DM. Lactobacillus species: taxonomic complexity and controversial susceptibilities. Clin Infect Dis. 2015;60(Suppl suppl_2):S98-S107. doi:10.1093/cid/civ072

16. Siegel CA, Whitman CB, Spiegel BMR. Development of an index to define overall disease severity in IBD.. Gut. 2018;67(2):244-254. doi:10.1136/gutjnl-2016-312648

17. Anjum N, Maqsood S, Masud T, Ahmad A, Sohail A, Momin A. Lactobacillus acidophilus: characterization of the Species and Application in Food Production. Crit Rev Food Sci Nutr. 2014;54 (9):1241-1251. doi:10.1080/10408398.2011.621169

18. Alex P, Zachos NC, Nguyen T, et al. Distinct cytokine patterns identified from multiplex profiles of murine DSS and TNBS-induced colitis. Inflamm Bowel Dis. 2009;15(3):341-352. doi:10.1002/ibd.20753

19. Kawada M, Arihiro A, Mizoguchi E. Insights from advances in research of chemically induced experimental models of human inflammatory bowel disease. World $j$ Gastroenterology. 2014;13:55932007.

20. Dou X, Gao N, Yan D, Shan A. Sodium Butyrate Alleviates Mouse Colitis by Regulating Gut Microbiota Dysbiosis. Animals. 2020;10 (7):1154. doi:10.3390/ani10071154

21. Zhang J, Chen X, Song J, et al. Preventive Effects of Lactobacillus plantarum CQPC07 on Colitis Induced by Dextran Sodium Sulfate in Mice. Food Sci Tech Res. 2019;25(3):413-423. doi:10.3136/ fstr. 25.413

22. Gao X, Schottker B. Reduction-oxidation pathways involved in cancer development: a systematic review of literature reviews. Oncotarget. 2017;8(31):51888-51906. doi:10.18632/oncotarget.17128
23. Shamoon M, Martin NM, O'Brien CL. Recent advances in gut Microbiota mediated therapeutic targets in inflammatory bowel diseases: emerging modalities for future pharmacological implications. Pharm Res. 2019;148(148):104344. doi:10.1016/j.phrs.2019.104344

24. Nishida A, Inoue R, Inatomi O, Bamba S, Naito Y, Andoh A. Gut microbiota in the pathogenesis of inflammatory bowel disease. Clinical Journal of Gastroenterology. 2018;11(1):1-10. doi:10.1007/ s12328-017-0813-5

25. Feng X, Zhang J, Qian Y, et al. Preventative effects of Lactobacillus plantarum YS-3 on oxazolone-induced BALB/c colitis in mice. App Biol Chem. 2018;61(3):355-363. doi:10.1007/s13765-018-0359-3

26. Vorobeva EV, Krasikova IN, Solov'Eva TF. Influence of lipopolysaccharides and lipids A from some marine bacteria on spontaneous and Escherichia coli LPS-induced TNF- $\alpha$ release from peripheral human blood cells. Biochemistry (Mosc). 2006;71(7):759-766. doi:10.1134/ s000629790607008x

27. Christ WJ, Asano O, Robidoux AL, et al. E5531, a pure endotoxin antagonist of high potency. Science. 1995;268(5207):80-83. doi:10.1126/science. 7701344

28. Chandrakasan S, Venkateswaran S, Kugathasan S. Nonclassic Inflammatory Bowel Disease in Young Infants: immune Dysregulation, Polyendocrinopathy, Enteropathy, X-Linked Syndrome, and Other Disorders. Pediatr Clin North Am. 2017;64 (1):139-160. doi:10.1016/j.pcl.2016.08.010

29. Miele E, Pascarella F, Giannetti E, Quaglietta L, Baldassano RN, Staiano A. Effect of a probiotic preparation (VSL\#3) on induction and maintenance of remission in children with ulcerative colitis. $\mathrm{Am}$ $J$ Gastroenterol. 2009;104(2):437-443. doi:10.1038/ajg.2008.118

30. Suo H, Zhao X, Qian Y, et al. Lactobacillus fermentum suo attenuates $\mathrm{HCl} /$ ethanol induced gastric injury in mice through its antioxidant effects. Nutrients. 2016;8(3):155. doi:10.3390/nu8030155

31. Chen X, Zhao X, Wang H, Yang Z, Li J, Suo H. Prevent Effects of Lactobacillus Fermentum HY01 on Dextran Sulfate Sodium-Induced Colitis in Mice. Nutrients. 2017;9(6):545. doi:10.3390/nu9060545

32. Szajewska H, Ruszczynski M, Kolacek S. Meta-analysis shows limited evidence for using Lactobacillus acidophilus LB to treat acute gastroenteritis in children. Acta Paediatr. 2014;103(3):249-255. doi:10.1111/apa.12487

33. Derwa Y, Gracie DJ, Hamlin PJ, Ford AC. Systematic review with meta-analysis: the efficacy of probiotics in inflammatory bowel disease. Aliment Pharmacol Ther. 2017;46(4):389-400. doi:10.1111/ apt. 14203
Drug Design, Development and Therapy

\section{Publish your work in this journal}

Drug Design, Development and Therapy is an international, peerreviewed open-access journal that spans the spectrum of drug design and development through to clinical applications. Clinical outcomes, patient safety, and programs for the development and effective, safe, and sustained use of medicines are a feature of the journal, which has also been accepted for indexing on PubMed Central. The manuscript management system is completely online and includes a very quick and fair peer-review system, which is all easy to use. Visit http://www. dovepress.com/testimonials.php to read real quotes from published authors. 